\title{
As contingências do trabalho bancário: Um estudo sobre os mecanismos de mediação e defesa do sofrimento
}

\author{
Anderson Gonsalves Jaques \\ Denise Macedo Ziliotto
}

\section{RESUMO}

O setor bancário sofre mudanças importantes desde a reestruturação produtiva na década de 90, implicando redução significativa no contingente de trabalhadores e transformações na organização do trabalho. Estas contingências impactam na saúde mental do bancário, sendo relevante investigar os mecanismos de mediação e defesa do sofrimento utilizados pelos trabalhadores diante deste contexto. Esta pesquisa descritiva, de abordagem qualitativa, foi realizada por meio de entrevistas com bancários de instituição privada de atuação nacional, submetidas à análise de conteúdo. A investigação identificou os efeitos da organização do trabalho, onde as premissas da gestão geram importante individualização do trabalho, pois o bancário é tensionado pela pressão da meta e pela necessidade de reconhecimento. Há mobilização subjetiva no sentido de tentar mediar o sofrimento decorrente da dinâmica do trabaIho, como evidenciado na superficialidade afetiva e no isolamento que busca dar conta da demanda de atribuições imposta, o que se reflete na condição de atendimento aos clientes. Dentre as estratégias de mediação presentes nas experiências dos participantes estão a cooperação, a inteligência prática e a transgressão; como mecanismos de defesa, foram identificados o cinismo viril, a insensibilidade afetiva, o isolamento e o adoecimento psíquico.

Palavras-chave: bancários; mecanismos de defesa; sofrimento psíquico; trabalhador.

\section{ABSTRACT}

\section{Contingencies of working in a bank: A study on the mechanisms of mediation} and defense aganist suffering

The banking sector has undergone remarkable changes since the production restructuring in the 1990s, which caused a significant decrease in the number of workers and changes in the work organization. Such contingencies have caused an impact on the mental health of bank workers, and it is important to investigate the mechanisms of mediation and defense against suffering used by workers in this context. In this descriptive, qualitative research, bank workers of a national private institution were interviewed. The interviews were subjected to content analysis. The research identified the effects of work organization, where the management assumption generates an important individualization of the work, since the banking workers are stressed by the pressure of the goal and the need for recognition. There is a subjective mobilization trying to mediate the suffering resulting from the work dynamics, as evidenced by an affective superficiality and the isolation that seeks to account for the demand for attributions imposed, which is reflected in the condition of customer service. The mediation strategies in the participants' experiences are cooperation, practical intelligence and transgression. Virile cynicism, affective insensitivity, isolation, and psychical illness were identified as defense mechanisms.

Keywords: bank workers; defense mechanisms; psychical suffering; worker.

Os modos de trabalhar presentes no setor bancário refletem as modificações do trabalho contemporâneo:o sistema financeiro sofreu importantes modificações nas últimas décadas, implicando em transformações na organização do trabalho. A expressiva redução do quadro de funcionários - baseada no desenvolvimento da tecnologia e modernização dos processos - somou-se ao aumento da exigência de capacitação dos profissionais. Decorre, portanto, a

\section{Sobre os Autores}

A.G.J.

orcid.org/0000-0003-1628-0329 Universidade Feevale - Novo

Hamburgo, RS

andersonjaques.seiva@gmail.com

D.M.Z.

orcid.org/0000-0001-9146-5425

Unilasalle - Canoas, RS

denise.ziliotto@unilasalle.edu.br

\section{Direitos Autorais}

Este é um artigo de acesso aberto e pode ser reproduzido livremente, distribuído, transmitido ou modificado, por qualquer pessoa desde que usado sem fins comerciais. 0 trabalho é disponibilizado sob a licença Creative Commons CCBY-NC.

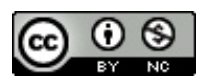




\section{MI* INTERACÃO EM PSICOLOGIA}

racionalização dos processos e o aumento da produtividade, sem que haja necessariamente incrementos na demanda de trabalho.

As inovações tecnológicas que a atividade bancário vem sofrendo aumentam a intensidade e o controle, juntamente com a introdução de processos flexíveis para remuneração e contratos que condicionam o trabalhador a um resultado independente da sua atividade; tais condições trazem insegurança salarial e contratual, moldando um novo perfil do trabalhador no setor (Malerba, 2011). Na perspectiva da reestruturação produtiva, emerge um novo modo de ser bancário queaos poucos é incorporada pelos sujeitos. Entre as principais consequências, encontram-se a instabilidade no emprego, a desvalorização das trajetórias dos profissionais na empresa, osrelacionamentos de curto prazo, o nomadismo involuntário e o sofrimento psíquico (Grisci, Cigerza, Hofmesiter \& Beckeret, 2006). No contexto da reestruturação produtiva, segundo Paiva e Borges (2009), os trabalhadores cedem à organização e gestão do trabalho e se alienam da busca de seus direitos socioeconômicos.

0 aumento da intensidade e na pressão no trabalho, somado às transformações no emprego bancário, resultam em novas práticas de trabalho, novos perfis de trabalhadores e em mudanças na carreira bancária. Na investigação de Rodrigues \& Sanches (2015), especialmente ao analisar as condições de trabalho dos profissionais, há a identificação do novo papel que precisam desempenhar no cotidiano de suas atividades: o de vendedores de produtos e serviços financeiros. Malerba (2011) indica ainda que novas práticas de gestão do trabalho bancário são introduzidas, visando a adesão e integração do trabalhador à ideologia do banco como a segmentação de clientes, dispositivos digitais para atendimento dos correntistas e usuários, novos instrumentos financeiros e a terceirização de várias atividades. Desta forma, a política dos bancos nas últimas décadas forja um trabalhador competitivo, focado no resultado e objetivos do banco, que responda às exigências do mercado. Também passa a ser alheio às organizações coletivas, pois será de seu próprio empenho individual que dependerá a sua remuneração, cada vez mais flexibilizada.

Diante destas questões que incidem sobre o setor bancário e sobre as relações nela existentes estabelece-se o objetivo da pesquisa, que é analisar os mecanismos de mediação e defesa do sofrimento utilizados pelos trabalhadores bancários, sendo processos presentes na organização do trabalho. Para tanto foi desenvolvida uma pesquisa de abordagem qualitativa e de característica descritiva, a partir de entrevistascom trabalhadores em agências de instituição bancária de atuação nacional na região metropolitana de Porto Alegre (RS).

\section{A DINÂMICA ECONÔMICA E O TRABALHO BANCÁRIO}

A análise das relações que se estabelecem entre o Estado e o sistema financeiro é um grande desafio para a compreensão da dinâmica capitalista contemporânea. Um dos fatores fundamentais que dimensionam o poder dos bancos e das instituições financeiras é o controle que estes exercem sobre parte substancial dos recursos e do fluxo de capitais na economia. Esse controle possibilita, em determinadas circunstâncias, criar pressões e cerceamentos ao processo decisório das políticas governamentais e às decisões estratégicas das empresas (Minella, 2007).

O lucro dos bancos bate recordes em função do produto comercializado ser altamente valorizado no país, sendo que a taxa de juros real é a segunda mais alta do mundo. A soma do lucro registrado por quatro bancos brasileiros em 2013, que chegou a cerca de US\$ 20,5 bilhões, é maior que o Produto Interno Bruto (PIB) de 83 países no mesmo ano, segundo levantamento feito com base em dados do Fundo Monetário Internacional (FMI). (Cury, 2015 a/2015b).

Para garantir seus lucros, os bancos obtêm seus resultados através de receita sobre venda, ou como explicita Malerba (2011): "A chamada 'área negocial' relacionada à venda de produtos e serviços financeiros passou a ser considerada prioridade absoluta dos bancos"(p. 12). Ou seja, os bancos, como instituições que visam o lucro, têm suas receitas obtidas através da oferta dos produtos não bancários (os seguros, as previdências, os títulos de capitalização) e os produtos bancários (linhas de crédito, as contas correntes e outros que compõem a diversificada oferta dos bancos comerciais).

$\mathrm{O}$ trabalhador bancário tem sido exposto a uma atividade que vem sofrendo, ao longo do tempo, diversas intervenções: reduçãodo quadro de funcionários, terceirização dos postos de trabalho e intensificação do uso da tecnologia. Atualmente, o trabalhador bancário exerce a função de executivo financeiro e leva a relação cliente-banco a outro patamar, pois é capaz de manipular e processar um grande conjunto de informações complexas, que vai da atual situação da economia brasileira até as características e limitações dos produtos bancários, encontrando a melhor solução para o cliente (Santos, 2010). Segundo o autor "isso faz com que o relacionamento acabe sendo personalizado na pessoa que faz o atendimento e, ao acompanhar toda a história do relacionamento, cria uma relação de confiança mútua" (p.27).

\section{SOPFIMENTO NO TRABALHO: MEDIAÇÃO E ESTRA- TÉGIAS DEFENSIVAS}

O trabalho não é apenas produzir algo, implica necessariamente na transformação do eu. Não é tampouco um proces- 


\section{H. INTERACÃO EM LF PSICOLOGIA}

so de relação individual entre o sujeito e a tarefa, pois se trabalha sempre com outros, em diferentes níveis de poder e relação. Com isso, o trabalho pode ter expressão e significado, a partir da contribuição ao grupo, da construção coletiva. Contudo, se predominar o sofrimento, os trabalhadores poderão utilizar as estratégias de mediação ou estratégias defensivas que possibilitam evitar o adoecimento e enfrentar uma organização do trabalho muitas vezes contraditória e adversa. As estratégias utilizadas para fazer frente ao sofrimento são produzidas na organização do trabalho, seja por meio da mobilização subjetiva ou por meio das estratégias defensivas (Silva \& Freitas, 2010).

Segundo Anchieta, Galinkin e Mendes (2011), o sofrimento pode ser enfrentado através de estratégias de mediação engendradas pelos trabalhadores, que têm como objetivo evitar a desestruturação e o adoecimento mental. A mobilização subjetiva exige o uso da inteligência prática e da cooperação, como no uso de "quebra galhos", havendo certa resignação do sofrimento. Quando a mobilização subjetiva não é eficiente para lidar com o sofrimento, ou seja, quando a organização do trabalho não oferece condições para a mobilização subjetiva, impera o uso de estratégias defensivas empregadas pelos trabalhadores, segundo Silva e Freitas (2011).

Segundo Dejours (1992), diante do sofrimento, o sujeito emprega defesas coletivas ou individuais que buscam controlar e evitar o adoecimento. Desta forma, apesar do ambiente e das pressões existentes, permanece em uma determinada normalidade aparente que encobre o sofrimento existente, denominada pelo autor como normalidade sofrente. 0 trabaIhador, frente às pressões organizacionais, consegue, graças às defesas, minimizar a percepção que ele tem destas pressões. Para Dejours, Abdoucheli e Jayet(2011), o funcionamento das estratégias defensivas forja uma relação subjetiva diante das pressões patogênicas, o que faz passar o trabalhador de vítima passiva para uma posição de desafio, em atitude provocadora ou minimizadora frente à pressão. Segundo os autores, em relação às estratégias coletivas de defesa, não pode ser conhecido o sofrimento nem o prazer de um grupo, uma vez que este é subjetivo e é sentido e vivido diferentemente por cada sujeito. Contudo, o que vários trabalhadores experimentam individualmente - e com isso são capazes de unir seus esforços para construir uma estratégia defensiva comum - funciona como regra, caracterizando as estratégias coletivas. A diferença entre um mecanismo de defesa individual e as estratégias coletivas de defesa, é que o primeiro está interiorizado persistindo mesmo sem a presença do outro, enquanto as estratégias coletivas de defesa não se sustentam a não ser por um consenso e, também são coordenadas e unificadas pelas regras defensivas, conforme foram nomeadas por Dejous (1992).
Os mecanismos de defesa podem tornar tolerável o sofrimento ético, o qual segundo Dejours (1992) "entende-se por tal não o sofrimento que resulta de um mal padecido pelo sujeito, e sim o que ele pode experimentar ao cometer, por causa de seu trabalho, atos que condene moralmente" (p.32). Deste modo, se este trabalhador conseguir desenvolver mecanismos contra este sofrimento ele conseguirá manter seu equilíbrio, como na execução de um trabalho condenado pela moral - o trabalho sujo - onde a participação consciente do sujeito em um ato injusto é resultado de uma atitude calculista para manter seu lugar, conservar seu cargo, sua posição, seu salário, suas vantagens e não comprometer seu futuro e até sua carreira.

A perspectiva coletiva das estratégias coletivas defensivas pode ser identificada em situações como a obrigação de fazer o "trabalho sujo", onde os trabalhadores que exercem posições de responsabilidade têm que enfrentar o grande risco de perder a sua identidade ética, tomando decisões que não se conciliam com seus preceitos morais. Neste contexto os gestores usam o cinismo - capacidade de fazer ainda mais do que o exigido, em termos de resultado, de expor números de enxugamento de pessoal priorizando e relacionando a produtividade, ou seja, produzir os mesmos resultados com um número menor de pessoas. Seus subordinados, movidos por estes discursos, cumprem seus objetivos, que são ostentados em reuniões gerenciais. As estratégias de defesa do cinismo viril estão ligadas ao reconhecimento pelo outro, ou seja, o reconhecimento do homem pelo homem, pois quem é reconhecido na contribuição que faz à organização agrega valor à sua identidade e transforma a si mesmo (Gernet, 2010).

Contudo, os profissionais não se sentem orgulhosos ao fazerem o "trabalho sujo"; pelo contrário, o fato de terem que participar de atos duvidosos à moral pode, inclusive, acarretar o sofrimento moral. Segundo Dejours (2001), para continuar a viver psiquicamente participando nesta condição e conservando o seu senso moral, os sujeitos que adotam estes comportamentos viris elaboram coletivamente ideologias defensivas, incorrendo na racionalização do mal.

Na perspectiva individual, as estratégias de defesa psíquicas impedem nos casos de lesões por esforço repetitivo (LER) e doenças osteomusculares relacionadas ao trabalho (DORTs), que os sujeitos percebam a dor e o adoecimento velado na relação com a organização do trabalho (Rossi, 2010). Outras incidências psíquicas, como a depressão e as ideações suicidas, relatadas no estudo de Santos, Siqueira e Mendes (2011), dimensionam o quanto os mecanismos de defesa deflagram a complexidade da experiência vivida pelo sujeito no trabalho. A falha nos mecanismos de defesa, aliada ao ritmo do trabalho e à redução da autonomia e da capacidade de 


\section{W NTERAC̄OOEM ET. PSICOLOGIA}

desenvolver um trabalho adequado e equilibrado a sua condição humana, pode causar danosimportantes ao aparelho psíquico (Dejours,1992).

\section{PERCURSO E CONTEXTO DA INVESTIGAÇÃO}

Para alcançar os objetivos propostos - investigar os mecanismos de defesa e mediação do sofrimento dos trabalhadores bancários - desenvolveu-se esta pesquisa de característica qualitativa e descritiva. A característica descritiva se justifica pela condição de planejamento e estruturação prévia da investigação, com o intuito de estudar as características de um grupo. A partir da descrição da população ou fenômeno eleitos para a pesquisa, é possível estabelecer relações entre as varáveis, possibilitando detalhamento das informações (Gil, 2008).

A coleta de dados se deu a partir da realização de entrevistas em profundidade com trabalhadores bancários de agências localizadas na região metropolitana de Porto Alegre (RS).

Trata-se de uma amostra intencional, por conveniência, em quatro agências de acesso aos pesquisadores, composta por seis participantes. Os entrevistados foram questionados como analisam o trabalho bancário, sobre suas atribuições e experiências profissionais no contexto da agência, acerca do estabelecimento de metas e sobre a equipe em que estão inseridos. Também refletiram sobre as dificuldades e limitações presentes na rotina de trabalho, e as mudanças percebidas no setor bancário no decorrer de sua prática profissional.

As entrevistas foram gravadas com o consentimento dos participantes e transcritas posteriormente, realizando-se uma leitura flutuante inicial para apropriação do conteúdo. Posteriormente, o material foi examinado a partir do sentido, perfazendo leituras transversais, como indica a análise de conteúdo proposta por Bardin (2011). Ao final deste processo foi realizada a categorização e agrupamento dos conteúdos significativo em temas - organização do trabalho, mecanismos de mediação e mecanismos de defesa do sofrimento - apresentados e analisados na próxima seção.

A organização em estudo tem atuação nacional, destacando-se no segmento e tendo na última década incorporado outros grupos menores, ampliando ainda mais sua atuação e lucratividade. Sua política corporativa tem como objetivos o respeito pelo cliente, a qualidade do trabalho, a ética e a responsabilidade, comprometimento da equipe, inovação, respeito ao trabalhador, estabelecendo como meta ser a maior instituição bancária do mundo.

As entrevistas foram realizadas no segmento de pessoa física, sendo participantes seis trabalhadores da área comercial de dois segmentos - varejo e individual. 0 primeiro segmento é responsável pelo atendimento a todos aqueles clientes e não clientes que vêm à instituição para resolver problemas, abrir conta, tomar crédito e aplicar recursos. Estes clientes são a maioria que compõe a carteira de uma agência e, por apresentar esta característica, o efetivo deste segmento é maior e recebe uma meta mensal e coletiva que é subdividida pelos trabalhadores que compõem 0 atendimento naquele mês. 0 segundo segmento - individual - é formado pelo grupo de clientes com renda elevada que compõe a carteira de clientes de um único gerente. Estes clientes são acompanhados com o objetivo de fidelizar e personalizar o seu atendimento; nesta modalidade o gerente recebe também uma meta mensal que é o único responsável pelo seu fechamento.

Inicialmente serão apresentados os participantes da pesquisa. E1: segmento varejo, solteira, escolaridade superior. E2: segmento varejo, solteira, escolaridade superior incompleta. E3: segmento varejo, solteira, escolaridade superior em curso. E4: segmento individual, casada, escolaridade superior. E5: segmento individual, escolaridade superior, divorciada. E6: segmento individual, casado, escolaridade superior.

\section{APRESENTAÇÃO E DISCUSSÃO DOS RESULTADOS}

\section{A ORGANIZAÇÃO DO TRABALHO SEGUNDO OS BANCÁRIOS}

Com o avanço da tecnologia e extinção de função intermediária entre os cargos de gerência e do caixa, configura-se a flexibilização e a sobrecarga de trabalho. Também fica evidente a pressão por produtividade em nome da eficácia e da lucratividade do banco, como explicita o entrevistado:

Eu acho que na realidade todo o trabalho tem metas, tem que correr atrás, mas acho que o que vem se diferenciando é a pressão, que cada vez tem que vender mais. Isso que eu acho que está mais acelerado com relação aos outros anos, porque eu sempre trabalhei, sempre fiz isso e sempre levei numa boa. Só que nos últimos anos a coisa está mais pegada. Isto do banco querer ser o melhor do mundo... antes se tinha mais apoio na retaguarda... Agora tu não tens nada. Quando acontece um troço no sistema tu não tens como resolver, tudo é contigo. (E2)

Segundo o entrevistado E3:

A rotina é forçada: que de tal hora a tal hora tem que fazer tal coisa... como no segmento individual, onde a gẹnte não é dona nem da organização do próprio trabalho. É um negócio muito mecânico, tu não és teu dono, tu és uma marionete.

A restrita autonomia em contrapartida às condições desfavoráveis para desenvolver o trabalho e alcançar as metas é uma experiência relatada pelos entrevistados. Segundo De- 


\section{H. INTERACÃO EM L PSICOLOGIA}

jours (1992) o sofrimento se inicia quando a relação homemorganização do trabalho está restrita; quando o trabalhador consumiu o máximo de sua capacidade intelectual, psicoativa, de aprendizagem e de adaptação. Quando um trabalhador utiliza de tudo de que dispunha de saber e de poder na organização do trabalho e quando ele não pode mais modificar a tarefa, isto é, quando foram consumidos os meios de defesas contra a exigência física. Este esgotamento que resulta em sofrimento também pode ser encontrado em:

Esta semana eu falei para uma senhora que queria desabafar sobre sua vida: - Minha senhora, vá embora eu tenho mais o que fazer. Tu já estás meio máquina daquilo que tem que fazer, que quando chega uma pessoa que te tira do teu curso, tu já queres mandar ela embora. Tu estás virando máquina; eu já trabalhei na época em que o gerente era um cara que te escutava. Hoje em dia não: tu queres aquele cliente que contrate o crediário e o seguro e vá embora porque tu tens que fechar. (E2)

Nesta situação o trabalhador fica tensionado com o tempo dispensado ao cliente que não lhe traz resultado aparente e pede para ele ir embora porque ele tem muitas atividades a realizar. Para Gaulejac (2011), o trabalhador pressionado pela meta e coisificado no ideal de sujeito-recurso, toma a atitude de escolher pela manutenção de sua sobrevivência na instituição, caracterizado pelo cumprimento da meta. Ou seja, o trabalhador, ao ser coagido pela pressão do trabalho, opta pela sua sobrevivência o que reporta a condição de sujeito recurso, que minimiza as interações e quaisquer demandas que Ihe reduzam a produtividade.

Esta individualização do trabalho e do resultado somada ao medo de ser demitido por não ser um trabalhador eficiente na visão da gestão fomenta o sentimento individualista no bancário:

A gente tenta não competir, mas o banco faz com que a gente seja cada vez mais individualista, cada um por si. Eu, às vezes fico feliz não por ter alcançado minha meta, mas sim por que o outro não alcançou, de saber que tem um pior do que eu. É um sentimento horrível. Ou seja, não é exatamente porque o outro não fechou, é porque se eu não consegui fechar, o outro também não fechou. Eu digo: ah, que legal! Mas é legal para mim e não para ele; se ele for melhor do que eu a cobrança será mais pesada em cima de mim. Então como é que um atinge e o outro não, tornando difícil de conseguir ter uma relação saudável com os colegas. Tem que ter uma cabeça muito boa porque quando tu percebes que uns não se dão... acaba um tentando passar a perna no outro porque o banco estimula isso... estimula uma concorrência desleal com o colega do lado que era para ser amigo, parceiro. (E4)

A pressão por desempenho promove também a competição, sendo passível sabotar e torcer pelo fracasso do colega, mas percebe-se que há sofrimento nesta condição, pois o trabalhador reconhece sua impropriedade. Gaulejac (2011) afirma que a ideologia gerencial atua sobre o corpo funcional que provocando uma ruptura interna entre o indivíduo-recurso que aceita se submeter para corresponder às exigências de seu emprego, e a porção do individuo-sujeito que resiste à instrumentalização. Esta ruptura pode ser encontrada em:

Eu acho que eu tento fazer a coisa certa, não sei se igual a todo mundo. Procuro ser honesta, ser transparente com as pessoas, mas eu noto que ultimamente eu nem tenho sido tanto assim sabe. Eu noto que a pressão está tanto assim que tem que ser muito superficial e tocar ficha, meio que enfiar goela abaixo. Não que eu ache certo, mas é o que ultimamente tem que ser. (E2)

É possível perceber que esta entrevistada está dividida entre fazer da maneira que sempre fez e julgou certo ou da maneira que corresponda aos objetivos da instituição, ao cumprimento de suas metas. Para Siqueira (2011, p.166) "A gestão pressiona cada vez mais o indivíduo, assimilando a sua subjetividade, de modo a torná-lo servo de todo um processo produtivo que o coisifica e impede, não raras vezes, a mobilização da sua criatividade profissional". Pode-se identificar os efeitos desta gestão no relato:

Na verdade, tu acabas obedecendo ao que tem que fazer se moldando a este formato devido ao medo de ser demitido. Eu tento ainda atender bem, porque sei que é uma pessoa que está na minha frente, mas não dá para fazer com todo mundo.(E3)

Gaulejac (2011) considera que a aceitação das regras impostas pela gestão aos trabalhadores é psiquicamente mais fácil na medida em que ela evita uma luta permanente contra a organização do trabalho, concedendo a este sujeito um mínimo de reconhecimento, pela manutenção de um emprego que permita assegurar a sua subsistência. A exigência para executar as tarefas de venda não deixa tempo necessário para o atendimento dos clientes, que muitas vezes recorre à instituição para pedir auxílio. 0 trabalhador é cobrado pela produção e de certa forma sente-se prejudicado quando precisa atender clientes não correntistas que não lhe trazem retorno, pois não são clientes propensos à venda. 0 espaço de conflito se estabelece especialmente no momento em que a pressão pelo fechamento da meta disputa espaço com o atendimento ao cliente.

Para Rossi (2010) o processo de saúde-adoecimento é caracterizado pelo jogo de forças entre as vivências de prazersofrimento e pelas estratégias que viabilizam a construção de sentido no trabalho. Este embate pode ser observado no relato:

A rotina mesmo passa a ser surreal porque eu não consigo seguir aquele parâmetro, fazer tudo aquilo que eles pedem. Talvez se eu não respirasse, se eu não comesse, se eu não fosse ao banheiro se eu nada, aí talvez eu conseguiria fazer tudo o que eles querem. Porque só de ligações que eles exigem - contando no roteiro deles - teria que ligar no mínimo para 25 pessoas por dia, e 25 pessoas para vender, não é só ligar dar bom dia e tchau... se esta pessoa me deu atenção eu vou ter que explicar, convencer e isso 


\section{W'INTERACÃO EM ET PSICOLOGIA}

se toma tempo. E 25 pessoas considerando que das quatro às seis o banco fica aberto e quando está aberto eu tenho que atender o público... Então, de todos aqueles que eu atendo durante o dia, eu tenho que ligar ainda para 25! Por isso, se outro cliente liga, que não fosse da minha lista, eu já perdia boa parte do tempo, porque eu não vou dizer para o cliente que agora eu não posso falar com ele. Porque não faz parte da minha lista, por mais que o banco nos oriente a fazer o cliente ligar para a central, o cliente não quer a central o cliente quer o gerente dele e muitos estão ali pelo atendimento do gerente e não da central do banco. (E4)

É exigência ao trabalhador bancário desenvolver um perfil de vendedor, para que empregue as estratégias mercadológicas e comercialize a imensa prateleira de produtos que os bancos possuem. Estes trabalhadores sofrem cada vez mais pressões para se manter empregados, tendo que recorrer a cursos, graduações e especializações fora do banco, os quais não garantem a sua estabilidade. Este tensionamento pelo cumprimento ou superação das metas podem induzir os bancários a comportamentos pouco transparentes ou mesmo anti - éticos (Maciel, 2010), como explícito em:

Na maioria das vezes para eu poder fechar minha meta que eles querem que eu feche, que tem que ser fechada não interessa o que o cliente quer e sim tem que ser o que "eu quero"! O que o banco me colocou de meta para aquele mês, às vezes nem é aquele produto o ideal, mas eu acabo direcionando para outro produto para poder fechar minha meta. (E4)

Outra perspectiva também é expressa neste relato: "... futuramente, no meu novo trabalho, eu não vou ter uma pessoa em cima de mim obrigando veladamente a vender desta forma! Como falou uma colega eu não vou precisar me corromper!" (E3)

Contra este sofrimento que o sujeito emprega ações no intuito de mediar e emprega defesas, buscando controlar e manter um estado de normalidade, denominada "normalidade sofrente", segundo Dejours (1992).

\section{MECANISMOS DE MEDIAÇÃO DO SOFRIMENTO}

Ao analisar o trabalho bancário foi possível perceber a mobilização subjetiva dos trabalhadores ao confrontar-se com as dificuldades de realização das tarefas, especialmente na cooperação entre os trabalhadores:

A gente procura dividir as metas para fluir melhor; pegamos o total da agência e dividimos entre os funcionários. 0 que um não consegue, o outro tenta compensar. As vezes tu tentas fechar a meta pelo telefone, percebe que ligou para aquela pessoa na semana passada e acaba saturando sem ter para quem ligar. E aí tu tens que buscar fora, de um conhecido, um amigo que tu sabes que tem conta... aí tu liga para ele e pede para ele fechar o produto, na parceria. (E1)

O mecanismo de mediação do sofrimento é visibilizado no uso da inteligência prática (Dejours, 2001) para o fecha- mento da meta. Neste funcionamento, o intuito é superar o sofrimento a partir da mobilização subjetiva, construindo soluções para os problemas vivenciados. Ao propor novas formas de organizar o trabalho o sujeito potencializa o exercício da inteligência prática, criando novas formas, mais eficazes, de desempenhar suas tarefas (Moraes, Vasconcelos \& Cunha, 2012). Na situação referida - o atingimento da meta - o trabalhador usa de sua astúcia para encontrar um possível comprador e então pede a ele para comprar o produto temporariamente. Ao fazer uso desta inteligência, no formato de "quebra galhos" como mediador do sofrimento, o sujeito arquiteta meios para que a organização do trabalho permita esta mobilização subjetiva. A coesão do grupo também é uma estratégia coletiva de defesa que garante, ao menos temporariamente, a proteção contra os efeitos do sofrimento sobre a saúde, pois permite as trocas, a transmissão de conhecimentos e descobertas (Merlo \& Barbarini, 2002). 0 uso da inteligência prática se manifesta em outros depoimentos como:

Muitas vezes eu procuro ser o ideal e acabo não fechando o que o banco quer. Fico me martirizando porque eu tento ser o ideal, mas o banco não quer que eu seja o ideal e sim que faça o real. $E$ o real é isso: vender, vender e vender. $E$ se o cliente aparecer com o problema devemos tentar mandar ele embora, fazer com que ligue para uma central, não perder tempo com ele porque com aquele problema eu vou perder tempo e não vou vender. Ou seja, pareço aquelas vendedoras de loja, em época de Natal, que tenta vender o máximo e se o cliente aparece para destrocar um produto informo que não posso ajudá-lo... que o senhor apareca aqui só depois do primeiro do ano, porque até lá quando tiver que fazer queima de estoque, a gente vê o que faz para o senhor. o que eu sinto é mais ou menos isso; não tem como descrever diferente. (E4)

Em função desta cobrança por um ideal inatingível - explícita nas metas pretendidas - a transgressão como forma de mediação do sofrimento se torna inevitável. No relato de E5 esta prática também toma outras proporções, pois para fechar as suas metas, realiza venda casada com algum produto que não faz diferença para o cliente como a aplicação em conta corrente de seu saldo. Mesmo não informando sobre o seu cadastramento, simplesmente solicita que assine ou coloque a senha. Esta prática também está presente para E6 que afirma ao ser questionado sobre o funcionamento das vendas: "Se tu não fizeres assim tu não bates tua meta e se tu não bates tua meta tu não ganhas tua variável para realizar seus sonhos".

Portanto, a mobilização subjetiva que os trabalhadores desenvolvem pode ser entendida como uma resposta à exigência de resultados mesmo sem as condições para o alcance das metas; o sofrimento justamente surge quando não é mais possível à negociação entre sujeito e a organização do trabalho (Mendes \& Facas, 2010). A estratégia se dá com o uso da inteligência prática, que corresponde ao investimento 


\section{n* INTERACÃO EM F PSICOLOGIA}

do corpo, da intuição, da percepção, de modos operatórios e afetivos utilizados pelos trabalhadores, como mecanismo de mediação do sofrimento ao transgredir o trabalho vivenciado. Para E4 esta transgressão ocorre quando rompe as barreiras morais do trabalhador:

Eu não sei te explicar esta forma que a gente faz no banco porque, às vezes, quando eu deito a cabeça no travesseiro e paro para pensar em uma "criatura" que não ganha muito e eu tentar empurrar um produto para ele, sabendo que ele precisa daquele dinheiro para comer... (E4)

A experiência produz neste trabalhador um segundo sofrimento que, segundo Silva e Freitas (2011), não é conformado, pois a mobilização subjetiva não é eficiente, prevalecendo o uso de estratégias como mecanismo de regulação da normalidade sofrente deste trabalhador. Esta dimensão será explicitada a seguir.

\section{MECANISMOS DE DEFESA DO SOFRIMENTO}

Entre as estratégias coletivas de defesa relatadas pelos participantes, identificou-se a estratégia de defesa do cinismo viril, segundo categorização de Dejours (2001). Para o autor as estratégias de defesa do cinismo viril estão relacionadas ao reconhecimento pelo outrem, ou seja, o reconhecimento do homem pelo homem. Ao pertencerem a um grupo de trabalhadores que corre o risco constante de perder seu emprego por baixa produção, incorrem no sentimento de vergonha por não serem eficientes, respondendo às expectativas da instituição. 0 uso destas práticas é expresso em:

Eu noto que a pressão está tanto assim que tem que ser muito superficial e tocar ficha, meio que enfiar goela abaixo. Não que eu ache certo, mas é o que ultimamente tem que ser. (E2)

Na venda de atendimento, a gente atocha os produtos nas pessoas que não querem. (E3)

A venda em muitos casos é empurrar, é apelar paro o cliente, não digo obrigar, porque obrigar os clientes não é o meu caso. (E4)

... por que o tipo de venda que a gente faz aqui não é uma venda normal. Eu brinco com meus colegas que a venda é uma empurroterapia, pois tu tens que convencer o cara que aquilo é legal. (E6)

É importante salientar que o uso destas práticas, são executadas e fomentadas também devido à pressão que o trabalho exerce, como relatam os entrevistados:

.. quando eu fui para uma agência menor pude desfrutar deste prazer de ser gerente. Mesmo vendendo eu era reconhecida pelo cliente, o que o fato de ser gerente resultava na venda. O que eu vejo de diferente hoje é que, antes se eu não fechasse um produto eu levantava a cabeça e ia à luta, ninguém me ameaçava que eu iria para a rua. Mas agora eu escuto a todo o tempo: se não fechar um mês eu vou para a rua, se não fechar dois meses eu vou para a rua, se não fechar três eu vou para a rua. Então eu nunca sei quando eu vou para a rua. A qualquer sinal diferente do chefe eu acredito que eu vou para a rua... se ele está diferente eu já paro e penso: será que ele vai me demitir. (E4)

....as pessoas estão adoecendo, estão a cada dia procurando outro trabalho, cada dia mais estressante. (E5)

A utilização destas práticas que causam prejuízo ao cliente e à instituição - a venda casada que no vocabulário dos bancários leva o nome de: goela abaixo, atochar os produtos, empurroterapia - ocorre quando o cliente não tem clareza da transação que está sendo realizada, configurando uma aquisição sem seu consentimento. Duas situações concorrem para estes procedimentos: primeiramente pelo reconhecimento como sujeito frente ao grupo, ou seja, não ser reconhecido como um fracassado pelos outros. 0 segundo motivo está relacionado à sobrevivência quanto trabalhador desta organização, ao medo de ser demitido. Porém o uso destas práticas para defenderem-se do sofrimento exercido pela pressão ou do reconhecimento como sujeito induz este trabalhador ao sofrimento moral. Para Dejours (1992) os trabalhadores para continuarem a viver psiquicamente participando do "trabalho sujo" na empresa e conservando o seu senso moral, adotam comportamentos viris ao elaboram coletivamente ideologias defensivas. Este sofrimento moral pode ser reconhecido no relato do entrevistado:

Se eu estivesse em uma loja eu acho que seria diferente... às vezes eu me sinto suja e em uma loja eu me sentiria mais limpa...Acredito para que não me sinta assim eu teria que sair do banco, porque agora é muito diferente de quando eu entrei, que era só trabalhar. Isso agora não se consegue, a pressão está cada vez maior e cada vez mais as pessoas estão fazendo desta forma para atingir o que eles querem. Por isso cada vez eu me sinto mais cansada, suja, sei até que vou usar uma palavra forte, mas eu sinto que estou me prostituindo... porque quando eu peço para uma pessoa - "pelo amor de Deus faz isso para me ajudar" me exponho deste jeito, me fragilizo na frente de um cliente. Eu me acho nojenta e mesmo que o cliente faça para me ajudar eu sinto que estou me prostituindo, fragilizada... não me sinto bem e não queria que fosse desta forma. (E4)

Diferentemente do primeiro contexto, onde os trabalhadores utilizam destas práticas como meio para ser reconhecido virilmente pelo grupo, onde são elaboradas coletivamente ideologias defensivas, no segundo momento estes trabalhadores usam destas práticas como meio de assegurar o seu trabalho. Não desenvolvem mecanismos para a defesa do sofrimento moral, ou se desenvolvem são pouco eficazes porque o sofrimento se evidencia como manifesta E4: "Às vezes a sensação que eu tenho é que a pessoa leva aquele produto que a gente está oferecendo é porque eu quero e não porque ele quer; então a diferença é como a gente se sente frente ao trabalho". 


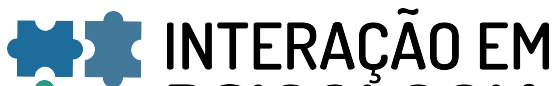 ET PSICOLOGIA}

Vivenciando o sofrimento advindo de questões morais e frente à obrigatoriedade de executar as práticas de venda do trabalho bancário, este trabalhador corre o risco de também de perder a sua identidade ética. Foi possível identificar os mecanismos de defesa presentes nestes trabalhadores, que têm a função de - "armadilhas" - ao diminuir a sensibilidade do trabalhador ao que lhe faz sofrer:

Eu tento ainda atender bem, porque sei que é uma pessoa que está na minha frente. Mas não dá para fazer com todos, mas não sou incoerente como outros que mandam colocar a senha. Esta corrupção, de inversão de valores é um conjunto do todo, porque estamos todos assim, tentando passar a perna no outro. (E3)

É perceptível que os mecanismos de defesa agem onde o trabalhador ignora a condição humana de seu cliente e o trata como objeto, ou seja, ignora este cliente porque precisa atender e produzir incondicionalmente, atingindo metas que garantem sua empregabilidade. Sato, Lacaz e Bernardo (2006), também identificaram que os trabalhadores bancários são submetidos a medo, humilhações, injustiças e até ilegalidades por parte dos bancos, muitas vezes sendo pressionados a agirem contrariamente a seus valores éticos e morais. É justamente a organização do trabalho bancário, contexto de competitividade e sobrecarga, que foi elemento fundamental no processo de adoecimento físico e mental dos trabalhadores participantes da investigação realizada pelos autores.

Tais considerações descrevem e, ao mesmo tempo, possibilitam reflexões acerca da organização do trabalho no setor bancário, especialmente para os profissionais que desenvolvem funções comerciais e de atendimento nas agências. São evidências que explicitam movimentos e efeitos das mudanças ocorridas neste segmento, especialmente aquelas que são protagonizadas pelos sujeitos, presentes nas relações de trabalho.

\section{CONSIDERAÇÕES FINAIS}

A pesquisa investigou o contexto do trabalho bancário tendo como objeto especialmente os mecanismos de mediação e defesa do sofrimento presentes na esfera dos bancos privados. A investigação de cunho qualitativo descritivo, utilizou-sede entrevistas como instrumento de coleta de dados,em instituição privada na região metropolitana de Porto Alegre (RS).

A investigação identificou os efeitos da organização do trabalho no cotidiano dos trabalhadores onde as premissas da gestão geram importante individualização do trabalho, pois o bancário é tensionado pela pressão da meta e pela necessidade de reconhecimento. Há mobilização subjetiva no sentido de tentar mediar o sofrimento decorrente da dinâmi- ca do trabalho, como evidenciado na superficialidade afetiva e no isolamento que busca dar conta da demanda de atribuições imposta, o que se reflete na condição de atendimento aos clientes.

A existência de mecanismo de mediação do sofrimento expressa no trabalho em grupo manifesta-se na divisão da carga de trabalho, na inteligência prática e na transgressão, como modalidades para lidar com as angústias advindas da pressão pelos resultados. Também foi possível observar o cinismo viril como estratégia relacionada ao reconhecimento do sujeito, também observada como defesa mediante o autoritarismo das metas e a instabilidade do emprego. Como mecanismos de defesa individuais presentes nos trabalhadores, evidenciou-se a instabilidade afetiva, o isolamentoe o adoecimento psíquico.

A abordagem de futuros estudos comparativos entre bancos privados e públicos, posições e atividades exercidas pelos bancários e corporações em que ocorreram fusões ou aquisições, podem ampliar o escopo de investigação acerca da organização do trabalho e do sofrimento no segmento bancário.

\section{CONTRIBUIÇÃO DE CADA AUTOR}

A.G.J e D.M Z contribuiram para a conceitualização e a redação do artigo. A.G.J. realizou a investigação. A supervisão e a visualização ficaram a encargo de D. M.Z.

\section{DECLARAÇÃO DE CONFLITOS DE INTERESSES}

Os autores declaram que não há conflitos de interesses na investigação e nem no artigo produzidos.

\section{REFERÊNCIAS}

Anchieta, V. C. C., Galinkin, A. L., Mendes, A. M. B., \& Neiva, E. R. (2011). Trabalho e riscos de adoecimento: Um estudo entre policiais civis. Psicologia: Teoria e Pesquisa, 27(2), 199-208. http://dx.doi.org/10.1590/S010237722011000200007

Bardin, L. (2011). Análise de conteúdo.São Paulo: Edições 70.

Cury, A. (2015a). Mesmo diante da crise, lucro dos bancos não para de crescer. Portal G1.

Cury, A.(2015b). Lucro somado de quatro bancos brasileiros é maior que o PIB de 83 países. Portal G1.

Dejours, C. (1992). A loucura do trabalho. (5 ed.) São Paulo: Cortez-Oboré.

Dejours, C. (2001). A banalização da injustiça social.(4 ed.) 


\section{N"INTERACÃO EM ET PSICOLOGIA}

Rio de Janeiro: FGV.

Dejours, C., Abdoucheli, E., \&Jayet, C. (2011). Psicodinâmica do trabalho. São Paulo: Atlas.

Gaulejac, V. (2011).Gestão como doença social. São Paulo: Ideias e Letras.

Gernet, I. (2010). Psicodinâmica do reconhecimento. Em A. Mendes; A. R. C. Merlo; C. F. Morrone, \& E. P. Facas (orgs.). Psicodinâmica e clínica do trabalho: Temas, interfaces e casos brasileiros (pp.61-76). Curitiba: Juruá.

Gil, A. C. (2008). Métodos e técnicas de pesquisa social (6 ed.). São Paulo, SP: Atlas.

Grisci, C. L. I., Cigerza, G. C., Hofmeister, P. M., \& Becker, J. L. (2006). Nomadismo involuntário na reestruturação produtiva do trabalho bancário. Revista de Administração de Empresas, 46(1), 27-40. https://dx.doi.org/10.1590/ S0034-75902006000100004

Maciel, H. W. P. (2010). As relações de trabalho nos bancos privados: Um estudo da política de gestão e o impacto sobre os bancários. Dissertação de mestrado em Administração. Universidade Federal da Paraíba. João Pessoa.

Malerba, P. E. S. (2011). As transformações do setor financeiro no Brasil: Os trabalhadores e a fragmentação da representação sindical. Dissertação de mestrado em Ciências Políticas. Universidade Estadual de Campinas. Campinas.

Mendes, A. M., \& Facas, E. P. (2010). Transgressão do trabalho prescrito como estratégia para transformar o sofrimento-estudo da inteligência prática. Em A. Mendes; A. R. C. Merlo; C. F. Morrone, \& E. P. Facas (orgs.). Psicodinâmica e clínica do trabalho: Temas, interfaces e casos brasileiros (pp.77-92). Curitiba: Juruá.

Merlo, Á. R. C., \&Barbarini, N. (2002). Reestruturação produtiva no setor bancário brasileiro e sofrimento dos caixas executivos: um estudo de caso. Psicologia \& Sociedade, 14(1), 103-122. http://dx.doi.org/10.1590/ S0102-71822002000100007

Minella, A. C. (2007). Maiores bancos privados no Brasil: Um perfil econômico e sociopolítico. Sociologias, (18), 100125. http://dx.doi.org/10.1590/S151745222007000200006

Moraes, R. D. de, Vasconcelos, A. C. L., \& Cunha, S. C. de P. da. (2012). Prazer no trabalho: o lugar da autonomia. Revista Psicologia Organizações e Trabalho, 12(2), 217227.
Paiva, C. S. D. L. de, \& Borges, L. de O. (2009). O ambiente de trabalho no setor bancário e o bem-estar. Psicologia em Estudo, 14(1), 57-66. http://dx.doi.org/10.1590/S141373722009000100008

Rodrigues, I. J., \& Sanches, A. T. (2015).Condições de trabalho no setor bancário.Cadernos, 28 de Agosto, 2(2), 11-38.

Rossi, E. Z. (2010). Análise clínica da organização do trabalho bancário e o processo de adoecimento por LER/DORT. Em A. Mendes; A. R. C. Merlo; C. F. Morrone, \& E. P. Facas (orgs.). Psicodinâmica e clínica do trabalho: Temas, interfaces e casos brasileiros (pp.381-395). Curitiba: Juruá.

Santos, M. A. F. S., Siqueira, M.V., \& Mendes, A. M. (2011). Sofrimento no trabalho e imaginário organizacional: Ideação suicida de trabalhadora bancária. Psicologia \& Sociedade, 23(2), 359-368. http://dx.doi.org/10.1590/ S1415-65552010000500010

Santos, R. L. P. dos (2010). Executivos na berlinda: vivência de frustração e medo no trabalho bancário. Dissertação de mestrado em Administração. Universidade Federal do Rio Grande do Sul. Porto Alegre.

Sato, L., Lacaz, F. A. de C., \& Bernardo, M. H. (2006). Psicologia e saúde do trabalhador: Práticas e investigações na Saúde Pública de São Paulo. Estudos de Psicologia (Natal), 11(3), 281-288. http://dx.doi.org/ 10.1590/S1413-294X2006000300005

Silva, F. H. E. \& Freitas, L. G. (2010). Organização do trabalho: prazer-sofrimento e estratégias de mediação do trabalho de programadores de faculdade via internet. Em A. Mendes; A. R. C. Merlo; C. F. Morrone, \& E. P. Facas (orgs.). Psicodinâmica e clínica do trabalho: Temas, interfaces e casos brasileiros (pp.433 -451). Curitiba: Juruá.

Siqueira, M. V. S. (2010). Gestão, violência e servidão nas organizações: contribuições da sociologia clínica e da psicodinâmica do trabalho. Em A. Mendes; A. R. C. Merlo; C. F. Morrone, \& E. P. Facas (orgs.). Psicodinâmica e clínica do trabalho: Temas, interfaces e casos brasileiros (pp.165-177). Curitiba: Juruá. 